\title{
Research Article \\ Effects of Inlet Pressure on Ignition of Spray Combustion
}

\author{
Jian Chen, ${ }^{1}$ Jianzhong $L i\left(\mathbb{D},{ }^{1}\right.$ and Li Yuan ${ }^{2}$ \\ ${ }^{1}$ Key Laboratory of Aero-Engine Thermal Environment and Structure, Ministry of Industry and Information Technology, Nanjing \\ University of Aeronautics and Astronautics, 29 Yudao St., Nanjing 210016, China \\ ${ }^{2}$ School of National Defense Engineering, The Army Engineering University of PLA, 88 Biaoying Rd., Nanjing, 210007 Jiangsu, China
}

Correspondence should be addressed to Jianzhong Li; ljzh0629@nuaa.edu.cn

Received 21 September 2017; Accepted 28 December 2017; Published 11 March 2018

Academic Editor: William W. Liou

Copyright (C) 2018 Jian Chen et al. This is an open access article distributed under the Creative Commons Attribution License, which permits unrestricted use, distribution, and reproduction in any medium, provided the original work is properly cited.

To evaluate the effects of inlet pressure on the ignition process of spray combustion, the images of the ignition process were recorded and the outlet temperatures were measured under inlet pressure of $0.04-0.16 \mathrm{MPa}$. The initial flame formation and flame propagation and the effects of the inlet pressure on the initial flame formation were observed. A variation of outlet temperature, flame propagation, initial time of outlet temperature rise, time of maximum temperature rise, and temperature rise rate was investigated. With increasing inlet pressure, the time of initial flame formation and time of maximum area growth rate of flame decrease and the centroid location move radially. The radial distances of the initial flame centroid gradually increased by about $13 \%, 5 \%, 6 \%, 12 \%, 57 \%$, and $24 \%$. The trace of flame centroid is determined from the distribution of fuel and is related to the initial SMD of the atomizer. The maximum temperature rise and temperature rise rate are determined by the rate of flame chemical reaction, rate of large drop evaporation, and fuel/air ratio. With increasing inlet pressure, the maximum temperature rise increased by $50 \%, 58 \%, 12 \%, 11 \%$, and $-9 \%$, respectively. Meanwhile, the rate of the temperature rise increased by about $47 \%, 54 \%, 11 \%, 11 \%$, and $-7 \%$, respectively.

\section{Introduction}

Spray combustion devices are widely used in many fields. The fuel is directly injected into the air flow, and the ignition is a complex process including the evaporation and blending of fuels. Therefore, many factors can affect the ignition performance. These factors have been studied more and thoroughly in the past few decades [1-9].

The successful ignition of a gas turbine engine includes three phases [10]: (1) the formation of a flame kernel with sufficient energy, (2) the generation of a flame from the flame kernel and propagation of the flame to the entire primary combustion zone, and (3) the propagation of the flame to the adjacent no combustion region in the combustion chamber. Continuous shooting of flame images by a high-speed camera is an effective method to study the ignition process. Marchione and Mastorakos [11, 12] experimentally studied the ignition process and ignition characteristics of spray combustion of $n$-heptane. The characteristics of the flame propagating upstream determined the success of the ignition. Ahmed and Mastorakos [2-4] studied the ignition process of a methane jet and found that the flame propagated upstream in the shape of a cylindrical surface after the initial flame kernel was formed. Philip et al. [13] used high-speed imaging to record the space-time flame structure and studied the dynamics of the light-round process. Deng et al. [14] experimentally studied the ignition and extinction of nonpremixed cool flame at elevated pressures in the counterflow and demonstrated the hysteretic nature of ignition and extinction of cool flames by flame images.

The ambient pressure has been mostly affected on ignition such as fuel atomization [15-20], minimum ignition energy [21-24], flame kernel propagation speed [25], and burning velocity [26]. The aero engine generally operates under a negative pressure at a high altitude, and the ignition performance is related to engine safety and reliability. When the altitude is 7000 meters, the ambient pressure will be reduced to about $0.04 \mathrm{MPa}$. Therefore, the effect of ambient 


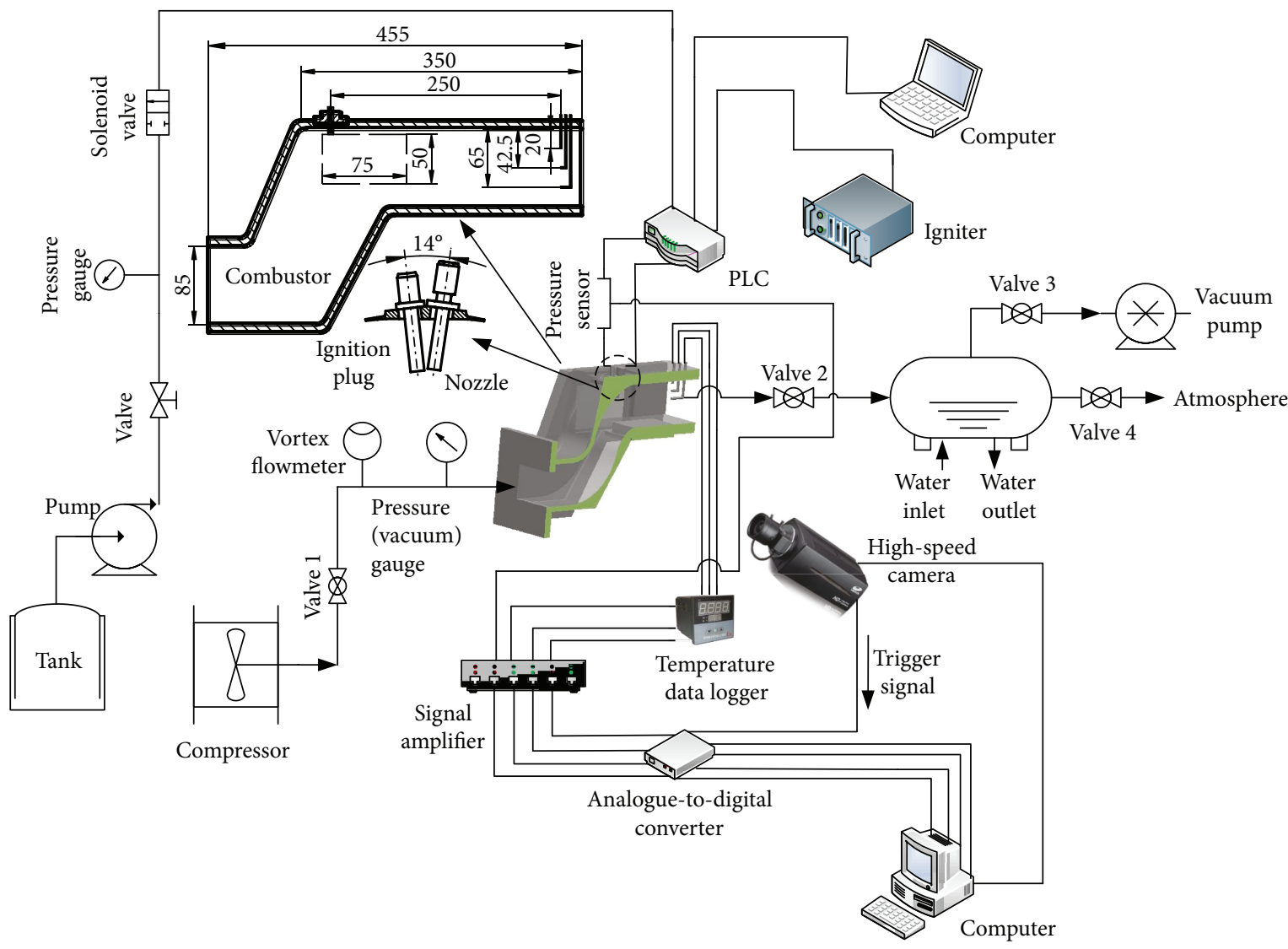

Figure 1: Test system for the ignition of spray combustion.

pressure on the ignition performance of an aero engine requires more attention, particularly when the ambient pressure is negative. Unfortunately, this issue has been poorly investigated and rarely reported. Keiichi et al.'s [27] experimental investigation of the ignition performance at high altitude conditions found that even for the highly flammable fuel it engenders difficulties related to ignition. Majcherczyk and Turrini [28] experimentally studied the influence turbulence length scale and intensity on spark ignition at high altitude relight conditions. The results showed that the energy required for flame kernel propagation is higher than for flame kernel generation. But the ignition process at the high altitude conditions did not demonstrate in their research.

In this study, RP-3 kerosene and air were selected as the fuel and oxidant, respectively. Under an inlet pressure of $0.04-0.16 \mathrm{MPa}$, the effects of inlet pressure on the ignition process and the ignition performance of spray combustion were studied with a high-speed camera and thermocouple measurement system. The effects of the variation in inlet pressure on the flame development process, temperature rise time of the combustion chamber exit, temperature rise, and temperature rise rate as well as the interactions among them were also analyzed. Moreover, the primary reasons responsible for the difference in the ignition process and ignition performance of the combustion chamber induced by the variation in inlet pressure were investigated.

\section{Experiment Description}

The test system for the ignition of spray combustion, as shown in Figure 1, mainly includes a gas supply system, a fuel supply system, an ignition system, a control system, a rectangular combustion chamber, thermocouples, a high-speed camera, and a temperature acquisition system.

The main research method of the ignition process was similar to those used in the previous experiments [2-4, 11-14]. Nevertheless, the method of the experiment includes some improvement. The temperature profiles at the combustion chamber exit were measured by three type $\mathrm{K}$ thermocouples (temperature range $0 \sim 800^{\circ} \mathrm{C}$, permissible error \pm $2.5^{\circ} \mathrm{C}$ ). The temperature signals were transmitted to the computer by the acquisition system to record the dynamic temperature (maximum error $\pm 0.5 \%$ ). Meanwhile, the acquisition system was synchronized with the high-speed camera.

The parameters of the combustion chamber are as follows: the total length is $455 \mathrm{~mm}$, sizes of both the inlet and outlet are $120 \mathrm{~mm} \times 85 \mathrm{~mm}$, and the centrifugal nozzle and spark plug centerline were installed on the same section with an angle of $14^{\circ}$. Three thermocouples were mounted on the same section at the outlet of the combustion chamber, and the axial distance between the thermocouple monitoring points and spark plug was $250 \mathrm{~mm}$. These three thermocouples denoted as TC-1, TC-2, and TC-3 were at $20 \mathrm{~mm}$, $42.5 \mathrm{~mm}$, and $65 \mathrm{~mm}$, respectively, away from the top surface of the combustion chamber. The air used in the test was 
obtained from a single screwed compressor. The air flow rate and air pressure were measured using a vortex shedding flowmeter (maximum error $\pm 1 \%$ ) and a pressure gauge or vacuum meter (maximum error $\pm 0.5 \%$ ) in front of the inlet of the combustion chamber, respectively. The fuel pressure was simultaneously measured using both the pressure gauges (maximum error $\pm 0.5 \%$ ) in front of the solenoid valve and pressure sensor (response time $\leq 1 \mu \mathrm{s}$ ) in front of the nozzle. To ensure the operation synchronicity between the highspeed camera and temperature acquisition system, the combustion chamber outlet temperature acquisition system was controlled using an internal trigger, that is, the temperature acquisition system was triggered by the voltage signal when the high-speed camera started working. The duration and frequency of the temperature acquisition were set as $8 \mathrm{~s}$ and $1 \mathrm{KHz}$, respectively.

The registration equipment is as follows: a high-speed CCD camera "IDT Y5" (image format $2336 \times 1728$ pixels, maximum frame rate $6900 \mathrm{fps}$ ), signal acquisition system "NI PXI-6135" (maximum acquisition frequency $1 \mathrm{MHz}$ ), and pressure sensor "PCB-113B26" (response time $\leq 1 \mu \mathrm{s}$ ). In addition, the SMD of the fuel spray near the spark plug was measured under ambient pressure and temperature by a Malvern laser particle size analyzer. Malvern laser particle size analyzer "Winner318A" (particle size 4.6 323 $\mu \mathrm{m}$, maximum error $\pm 3 \%$ ). The Malvern laser particle size analyzer is based on the scattering principle of light to measure particle size. It is characterized by wide dynamic range, rapid measurement, and convenient operation, especially suitable for measuring the liquid droplets with a wide range of particle size distribution. Similar to this, particle tracking velocimetry (PTV), laser Doppler velocimeter (LDV), and phase Doppler particle analyzer (PDPA) can also measure the particle size of the fuel spray. However, the distribution of particle size near the spark plug is the most concerned in the ignition $[1,5,10]$. The advantage of a Malvern laser particle size analyzer is that the distribution of particle size in the space of the laser beam near the spark plug can be more rapid and easier obtained. So we choose the Malvern laser particle size analyzer as the device for measuring the diameter of the fuel spray.

The shooting definition of the high-speed camera is $1680 \times 1128(1000 \mathrm{fps})$, and the size of the shooting window size was $75 \mathrm{~mm} \times 50 \mathrm{~mm}$. To coordinate the fuel supply system with the ignition system, a programmable logic controller (PLC) was used for active control so that the fuel supply system and ignition system started at the same time and stopped after $3 \mathrm{~s}$. The start/stop time of the fuel supply system and ignition system was acquired as a voltage signal using a computer. The fuel injection time of the nozzle was obtained using the pressure sensor in front of the nozzle, and the spark plug discharging time was obtained from the images recorded by the high-speed camera. Figure 2 shows the time sequence of ignition, in which $t_{\text {open }}$ is the start time of the fuel supply system and ignition system, $t_{\text {close }}$ is the stop time of the fuel supply system and ignition system, $\Delta t_{\mathrm{w}}$ is the operation duration of the fuel supply system and ignition system, $t_{\mathrm{f}}$ is the fuel injection time of the nozzle, $t_{\mathrm{ig}}$ is the spark plug discharging time, $t_{\text {end }}$ is the stop time of the data acquisition, $t_{\text {start }}$ is the initial time when the temperature rise of

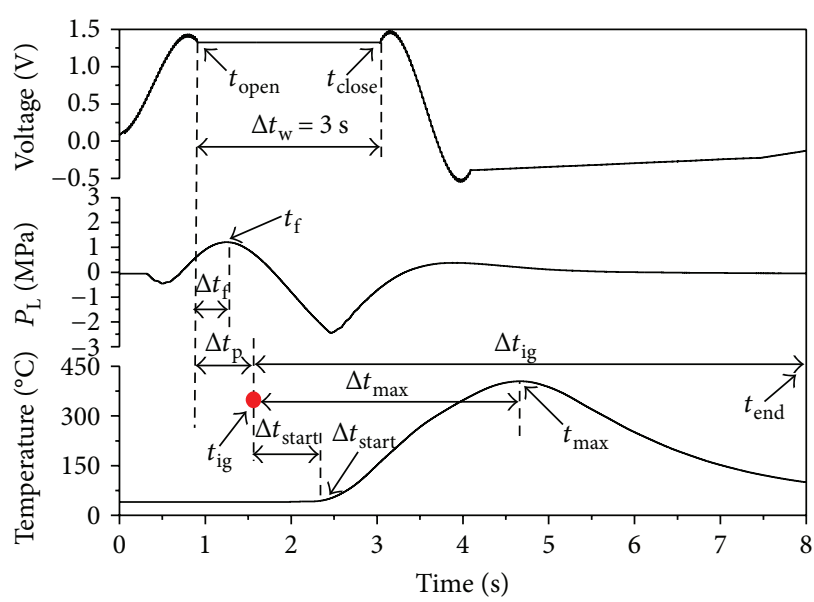

FIGURE 2: Schematic of ignition time sequence.

thermocouple can be observed, $t_{\max }$ is the time when the thermocouple temperature reached the maximum, $\Delta t_{\mathrm{ig}}$ is the time difference between the data acquisition and spark plug discharging, $\Delta t_{\text {start }}$ is the interval between the initial time of thermocouple temperature rise and the spark plug discharging time, $\Delta t_{\max }$ is the interval between the time when the thermocouple temperature reaches the maximum and the spark plug discharging time, $\Delta t_{\mathrm{f}}$ is the interval between the start time of the fuel supply system and ignition system and the fuel injection time of the nozzle, and $\Delta t_{\mathrm{p}}$ is the interval between the start time of the fuel supply system and ignition system and the spark plug discharging time. Among these, $\Delta t_{\mathrm{f}}$ is related to the injection pressure difference across the nozzle $\Delta P_{\mathrm{L}}$, and $\Delta t_{\mathrm{p}}$ is irrelevant to the external factors. Based on the statistics of the test results, when $\Delta P_{\mathrm{L}}=0.8 \mathrm{M}$ $\mathrm{Pa}, \Delta t_{\mathrm{f}}=0.346 \pm 0.001 \mathrm{~s}$, and $\Delta t_{\mathrm{p}}=0.82 \pm 0.001 \mathrm{~s}$, that is, after the fuel supply system and ignition system were opened, the fuel injection of the nozzle was $0.474 \mathrm{~s}$ ahead of spark plug discharging.

The test parameters were determined by the ignition conditions of the medium and small helicopter engines. RP-3 kerosene was used as the fuel in the test, in which the fuel properties are described in Table 1 . The inlet air flow velocity of the combustion chamber was set as $V=8 \mathrm{~m} / \mathrm{s}$ (reference the flow rate and area of the inlet), the ignition energy was set as $E=0.4 \mathrm{~J}$, the ignition frequency was set as $f=2 \mathrm{~Hz}$, and the injection pressure difference across the nozzle was set as $\Delta P_{\mathrm{L}}=0.8 \mathrm{MPa}$. The inlet pressure of the combustion chamber was set as $P_{\mathrm{t} 3}=0.04 \mathrm{MPa}, 0.06 \mathrm{MPa}, 0.08 \mathrm{MPa}$, $0.1 \mathrm{MPa}, 1.2 \mathrm{MPa}, 1.4 \mathrm{MPa}$, and $1.6 \mathrm{MPa}$. Under a quiet atmosphere, when $\Delta P_{\mathrm{L}}=0.8 \mathrm{MPa}$, the spray cone angle was $52^{\circ}$, and the mass flow rate was $m_{\mathrm{f}}=1.48 \mathrm{~g} / \mathrm{s}$.

In the ignition tests under standard atmosphere and high pressure, valve 3 was shut, and valve 4 was opened first. When the compressor started supplying air, valves 1 and 2 were adjusted simultaneously. When the inlet flow rate and pressure of the combustion chamber reached the desired operating point, the ignition test was started. In the lowpressure test, valve 4 was shut first, and valves 2 and 3 were opened. When the compressor and vacuum pump started 
TABLE 1: Fuel properties.

\begin{tabular}{ccccccc}
\hline Fuel & Specific gravity at $20^{\circ} \mathrm{C}$ & \multicolumn{2}{c}{ Viscosity $\left(\mathrm{mm}^{2} / \mathrm{s}\right)$} & $\begin{array}{c}10 \% \text { boil-off } \\
\text { Temperature }\left({ }^{\circ} \mathrm{C}\right)\end{array}$ & $\begin{array}{c}50 \% \text { boil-off } \\
\text { Temperature }\left({ }^{\circ} \mathrm{C}\right)\end{array}$ & $\begin{array}{c}100 \% \text { boil-off } \\
\text { Temperature }\left({ }^{\circ} \mathrm{C}\right)\end{array}$ \\
\hline RP-3 & 0.83 & 8.0 & 1.25 & 205 & 232 & 300 \\
\hline
\end{tabular}

working, valves 1 and 3 were adjusted simultaneously. When the inlet flow rate and pressure of the combustion chamber reached the desired operating point, the ignition test was started. Besides, to prevent the damage of the vacuum pump by the high-temperature gas generated by the combustion in the combustion chamber, the chamber connected to the outlet of the combustion chamber should be cooled via water injection. The high temperature in the combustion chamber after the combustion would affect the following test. To avoid such an effect, cooling blowing was carried out for 5-10 min to cool the combustion chamber after each test, and the next test was carried out when the thermocouple temperature became stable and reached the ambient temperature.

\section{Results and Discussion}

In the ignition test, the flame development process was recorded by the high-speed camera. Then, threshold segmentation of the images was conducted for extracting and analyzing the flame outline. The program was compiled using MATLAB. A proper threshold value led to an accurate segmentation of the flame pattern, and, simultaneously, the shape and size of the flame were maintained. Particularly, when the heat yielding intensity of the flame was relatively low, the illumination of the flame in the original image was too low to recognize the details of the flame. After the threshold segmentation, the details can be observed as shown in Figure 3. The threshold value for the image segmentation was determined using Otsu's method. Different images were selected based on the flame development speed under different operating conditions. When $P_{\mathrm{t} 3}=0.04-0.16 \mathrm{MPa}$, the images at $t=1-20 \mathrm{~ms}, t=1-20 \mathrm{~ms}$, $t=1-17 \mathrm{~ms}, t=1-17 \mathrm{~ms}, t=1-17 \mathrm{~ms}, t=1-17 \mathrm{~ms}$, and $t=$ $1-15 \mathrm{~ms}$ were selected, respectively, where $t=1 \mathrm{~ms}$ is the spark plug discharging time.

Figure 3 shows that the images at $P_{\mathrm{t} 3}=0.04 \mathrm{MPa}$ represent the ignition failure conditions. When the discharging of the spark plug is completed, the initial flame kernel was formed by a rapid reaction of the spark with the combustible gas around the spark plug. The initial flame released heat for enhancing the fuel evaporation and improving the rate of reaction heat release. At the same time, the heat was released in the air. Thus, the flame kernel gradually shrank at first, and the illumination decreased gradually. A low inlet pressure decreases the chemical reaction rate, and therefore the reactive heat release of flame kernel is low. When the reactive heat release could not sustain fuel evaporation for maintaining the development of a flame kernel, the flame kernel moved downstream with air flow and eventually extinguished. The remaining successful ignition images have the same feature, that is, when the initial flame kernel was formed around the spark plug, the flame kernel shrank, and the illumination decreased gradually at first. Then, at a certain position around the spark plug, the flame kernel grew, and the illumination gradually increased. Finally, a stable flame was formed at this location and propagated axially and radially in the combustion chamber. With the increase in inlet pressure, the initial flame kernel moved downwards in the combustion chamber in the development process, and the development speed of the flame was accelerated. Thus, the illumination was enhanced simultaneously with the development of the flame.

During combustion, the variation in the flame area is closely interrelated to the flame propagation speed. Generally, in the flame propagation process, the flame area gradually increases, corresponding to a persistent increase in the highlighted zone in the image. Because a digital image is composed of many pixels with identical areas, the area can be derived by first separating the target object by the binary processing of the image and then counting the total number of pixels of the target object in image processing, and the equation can be expressed as follows:

$$
S=S_{I} \times \sum I_{i}
$$

where $S$ is the total area of the target object, $S_{I}$ is the area of a single pixel, and $I_{i}$ is the number of pixels in the flame zone. The change rate of the flame area reflects the variation rate of the flame area. The image at the first frame represents the condition when the ignition plug struck the light $(t=1 \mathrm{~ms})$, and the formula for the change rate can be expressed as follows:

$$
\frac{\Delta S}{S_{i}}=\frac{S_{i+1}-S_{i}}{S_{i}}
$$

where $\Delta S / S_{i}$ is the growth rate of the flame area, $S_{i}$ is the flame area in the image at the $i$ th frame, and $S_{i+1}$ is the flame area in the image of the $(i+1)$ th frame.

Figure 4 shows that the trends of the flame areas in the ignition process are consistent. After the discharge of the spark plug, the area of the initial flame kernel first decreased, but the decrease gradually slowed down in the development process. After the initial flame was formed, the flame area grew, and the growth rate of the flame area rapidly increased to the maximum. Finally, although the flame area continued growing, the growth rate of the flame area decreased and became stable. When $P_{\mathrm{t} 3}=0.04 \mathrm{MPa}$, after the discharge of the spark plug, the development of the initial flame kernel lasted for $5 \mathrm{~ms}$, and the growth rate of the flame area increased from -0.87 to -0.08 . A positive growth started from $6 \mathrm{~ms}$ at a growth rate of 0.09. Subsequently, the flame area grew slowly, and the growth rate of flame area reached the maximum of 0.59 at $12 \mathrm{~ms}$. 


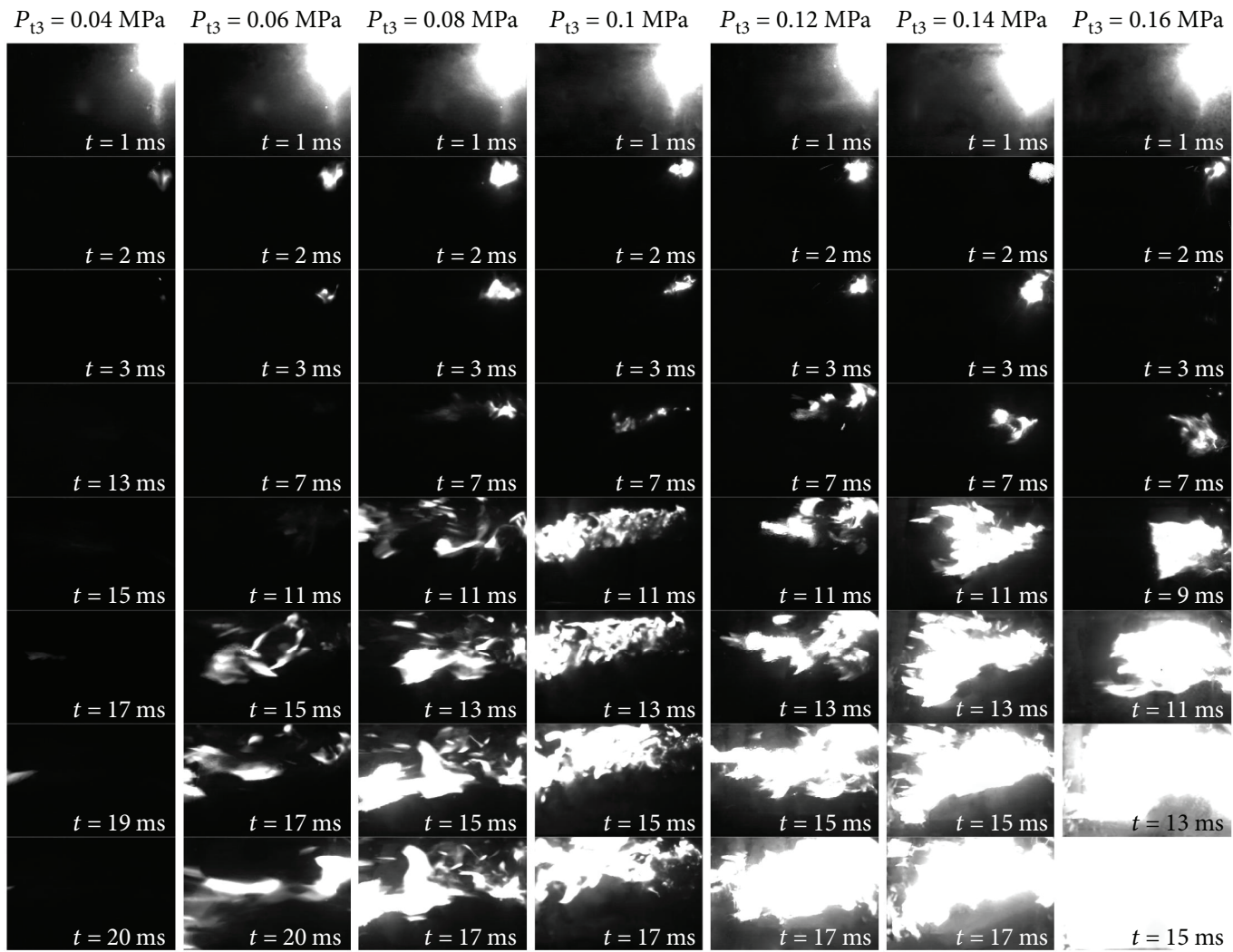

(a)

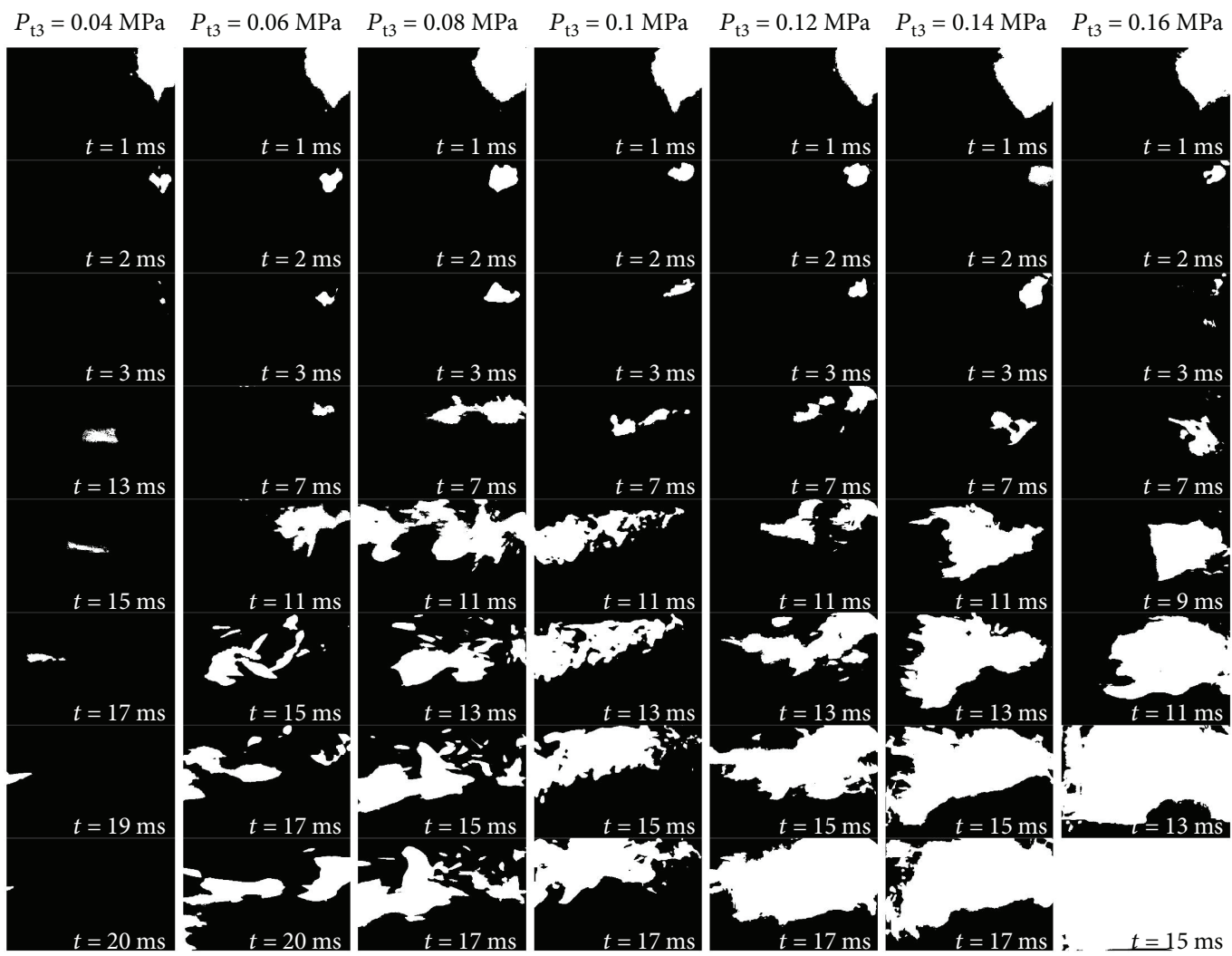

(b)

FIGURE 3: Flame development process with different inlet pressure. (a) Images recorded by a high-speed camera and (b) graphs done with threshold segmentation method. 


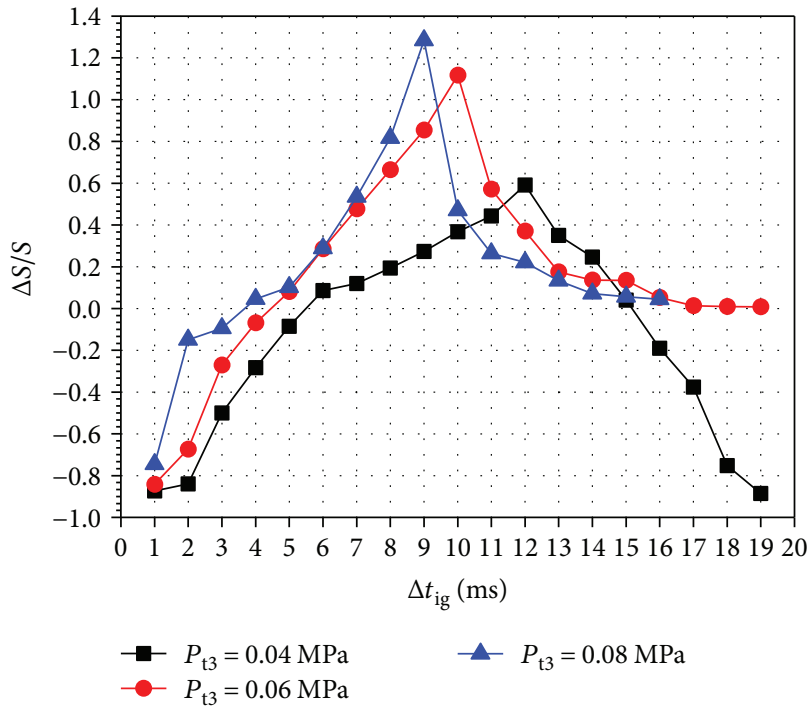

(a)

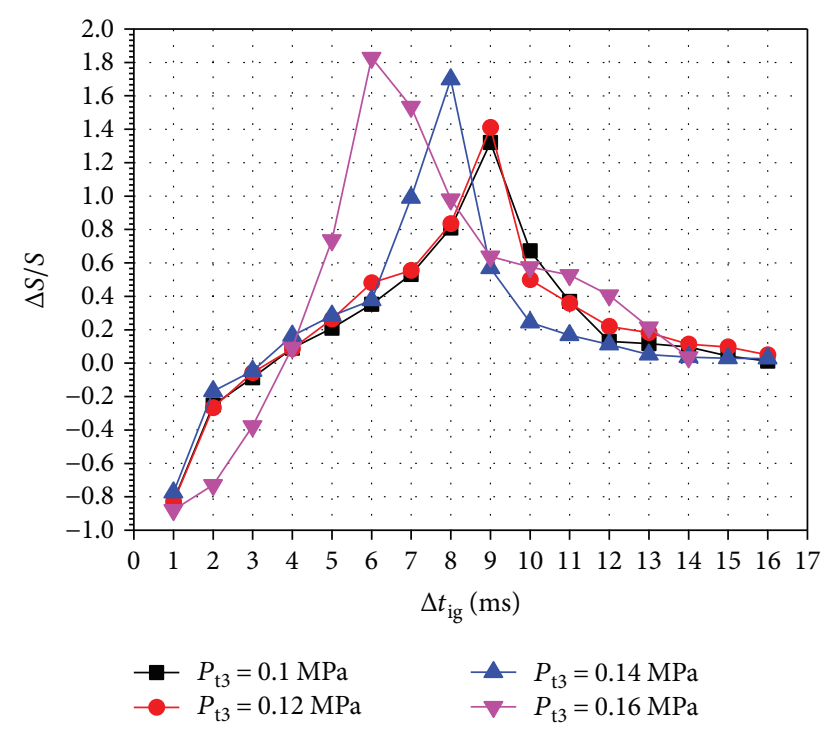

(b)

Figure 4: Effect of inlet pressure on the growth rate of the flame area. (a) $P_{\mathrm{t} 3}=0.04-0.08 \mathrm{MPa}$ and (b) $P_{\mathrm{t} 3}=0.1-0.16 \mathrm{MPa}$.

Finally, the growth rate of the flame area decreased rapidly and reached -0.19 at $16 \mathrm{~ms}$. The results show that the flame released more heat to ambient air flow than the heat generated from the reaction. Therefore, the flame was extinguished eventually, that is, the ignition failed. When $P_{\mathrm{t} 3}=$ $0.06 \mathrm{MPa}$, after the discharge of the spark plug, the development of the initial flame kernel lasted for $4 \mathrm{~ms}$, and the growth rate of the flame area increased from -0.84 to -0.06 . A positive growth started from $5 \mathrm{~ms}$ at a growth rate of 0.08 . Subsequently, the flame area grew slowly, and the growth rate of the flame area reached the maximum of 1.12 at $10 \mathrm{~ms}$. Finally, the growth rate of the flame area decreased rapidly and reached 0.008 . When $P_{\mathrm{t} 3}=0.08-0.16 \mathrm{MPa}$, the development of the initial flame kernel lasted for $3 \mathrm{~ms}$, and the initial flame kernel evolved into the initial flame at $4 \mathrm{~ms}$. The initial flame area grew rapidly, and the times required for the area growth rate reaching the maximum were $9 \mathrm{~ms}, 9 \mathrm{~ms}, 9 \mathrm{~ms}, 8 \mathrm{~ms}$, and $6 \mathrm{~ms}$, whereas the maxima were $1.28,1.32,1.41,1.69$, and 1.82 . Therefore, with the increase in inlet pressure, the maximum growth rate of the flame area increased. When $P_{\mathrm{t} 3} \geq 0.14 \mathrm{MPa}$, the time when the growth rate of the flame area occurred shifted to the earlier time. Moreover, when $P_{\mathrm{t} 3}=0.16 \mathrm{MPa}$, the initial flame kernel shrank significantly in the development process, and the area growth rate varied from -0.88 to -0.38 .

Based on the variation of growth rate of the flame area as shown in Figure 4, the ignition process can be divided into the following three phases: (1) formation phase of the initial flame. The period before the growth rate of the area became positive. In this phase, the heat released by the initial flame kernel was mainly used for fuel evaporation, thus accelerating the chemical reaction rate. (2) High-speed development phase of flame, the period between the growth rates of the area became positive and reached the maximum. In this phase, after the initial flame was formed, the increased intensity of heat release increased the fuel evaporation rate, and the increase in the fuel evaporation rate further strengthened the heat release of flame. Under the action of this positive feedback, the chemical reaction rate of the flame increased rapidly, exhibiting a rapid growth of the flame area. (3) Stable development phase of the flame, it is the period when the growth rate of the flame area started to decrease. In this phase, small drops rapidly evaporated to participate in combustion, and large drops continually evaporated to participate in combustion, leading to a gradual increase in the flame area at a declining growth rate.

The centroid is the geometrical center of an object. In this study, the concept of the centroid was introduced and applied to flame image processing, and the propagation direction of the flame was determined from the motion trace of the flame centroid in the image. The centroid of a binary image can be written as follows:

$$
\begin{aligned}
& x=\frac{1}{n} \sum x_{i}, \\
& y=\frac{1}{n} \sum y_{i},
\end{aligned}
$$

where $x$ and $y$ are the horizontal and vertical coordinates of the centroid, $x_{i}$ and $y_{i}$ are the horizontal and vertical coordinates of the pixel in the flame zone, and $n$ is the number of pixels in the flame zone.

Relative coordinates are used in the image processing of a centroid, that is, the centroid location of the spark when the spark plug discharged under each operating condition was regarded as the origin of coordinates. The axial direction along the combustion chamber downstream and the radial direction along the bottom wall were denoted as the $X$ and $Y$ directions, respectively. As shown in Figure 5, the motion distance of the initial flame kernel near the ignition plug is small, and the centroid coordinates of the initial flame are 12.9 , 2.77; $4.37,3.13 ; 3.85,3.3 ; 3.47,3.51 ; 3.32,3.95 ; 2.75$, 


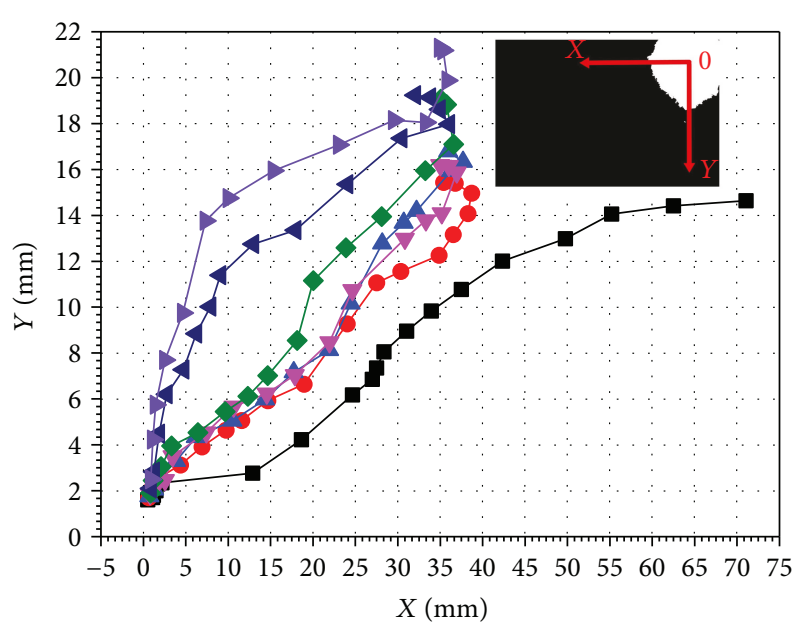

$$
\begin{array}{ll}
\longrightarrow P_{\mathrm{t} 3}=0.04 \mathrm{MPa} & -P_{\mathrm{t} 3}=0.12 \mathrm{MPa} \\
-P_{\mathrm{t} 3}=0.06 \mathrm{MPa} & -P_{\mathrm{t} 3}=0.14 \mathrm{MPa} \\
-P_{\mathrm{t} 3}=0.08 \mathrm{MPa} & \rightarrow P_{\mathrm{t} 3}=0.16 \mathrm{MPa} \\
\neg P_{\mathrm{t} 3}=0.1 \mathrm{MPa} &
\end{array}
$$

Figure 5: Effect of inlet pressure on the flame propagation trace of the flame centroid.

6.2; and 2.55, 7.7. After the initial flame was formed, as the inlet pressure increased, the flame centroid propagated radially farther in the combustion chamber. When $P_{\mathrm{t} 3}<0.14 \mathrm{M}$ $\mathrm{Pa}$, after the initial flame was formed, the flame centroid propagated rapidly along the axial direction of the combustion chamber downstream. When the growth rate of the area reached the maximum, the radial propagation of the flame centroid started to increase. When $P_{\mathrm{t} 3} \geq 0.14 \mathrm{MPa}$, the propagation trend of the flame centroid is opposite to the condition when $P_{\mathrm{t} 3}<0.14 \mathrm{MPa}$, and the flame centroid coordinates when the growth rate of area reached the maximum are $31.05,8.96 ; 18.95,6.65 ; 21.9,8.13 ; 21.95,8.47$; $17.1,9.35$; 9.06, 11.39; and 7.33, 13.76. Moreover, as shown in the image when the ignition succeeded in the combustion chamber, after the initial flame was formed, the flame propagation accelerated, leading to the axial and radial motions of the flame centroid towards the combustion chamber downstream. When the centroid propagated to a certain location, the propagation speed of the flame was higher than air flow velocity, and thus the recirculation of flame to combustion chamber upstream appeared, causing the flame centroid to move towards the combustion chamber upstream. When $P_{\mathrm{t} 3}=0.06-0.16 \mathrm{MPa}$, the recirculation time of the flame centroid occurred at $17 \mathrm{~ms}, 15 \mathrm{~ms}, 14 \mathrm{~ms}, 14 \mathrm{~ms}, 13 \mathrm{~ms}$, and $12 \mathrm{~ms}$ after the discharge of the spark plug, and the coordinates of the centroid recirculation points are 38.71, 14.96; $37.7,16.33 ; 36.97,15.87 ; 36.6,17.09 ; 36.05,17.97$; and 35.85 , 19.15, respectively. Hence, as the inlet pressure increased, the time when the recirculation of the flame centroid appeared and the axial motion distance towards the combustion chamber downstream was reduced. When $P_{\mathrm{t} 3}=0.04 \mathrm{MPa}$, no circulation of the flame centroid was observed. The flame centroid moved towards the combustion chamber downstream with air flow and eventually disappeared at the edge of the shooting window. This shows that no sufficiently developed flame was established in the combustion chamber, and the ignition failed.

For the thermocouples located at the combustion chamber exit, the starting time of temperature rise and time of maximum temperature rise are defined as the lag between the spark plug discharging time and starting time of the temperature rise of thermocouple and the lag between the spark plug discharging time and time when the thermocouple temperature reached the maximum. Figure 6 shows that as the inlet pressure increased, the starting time of the temperature rise of the thermocouples at the combustion chamber exit gradually decreased. The starting time of the temperature rise of TC- 1 is always the smallest and that of TC-3 is the largest. The starting time of the temperature rise of TC- 1 decreased from 0.499 to 0.286 , that of TC-2 decreased from 0.539 to 0.29 , and that of TC-3 decreased from 0.624 to 0.303 . Moreover, as the inlet pressure increased, the difference in the starting time of the temperature rise of TC- 1 to TC- 3 gradually decreased; particularly when $P_{\mathrm{t} 3} \geq 0.12 \mathrm{MPa}$, the difference decreased significantly. When $P_{\mathrm{t} 3}=0.04 \mathrm{MPa}$, because the ignition failed in the combustion chamber, the flame rapidly moved downstream with air flow, and the time of maximum temperature rise at the combustion chamber exit was relatively small. Effect of inlet pressure on the time of temperature rise at the combustion chamber exit is shown in Figure 7. When $P_{\mathrm{t} 3} \geq 0.06 \mathrm{MPa}$, the times of the maximum temperature rise of all the thermocouples at the combustion chamber exit were approximately $3 \mathrm{~s}$. Nevertheless, the times of the maximum temperature rise of these three thermocouples varied slightly. Among them, the time of the maximum temperature rise of TC- 1 varied most significantly, whereas those of TC-2 and TC-3 increased slightly (specifically, that of TC-2 increased from $3.026 \mathrm{~s}$ to $3.051 \mathrm{~s}$ and that of TC-3 increased from $2.929 \mathrm{~s}$ to $2.982 \mathrm{~s}$ ). When $P_{\mathrm{t} 3}=0.06-0.12 \mathrm{MPa}$, the time of the maximum temperature rise of TC-1 slightly decreased from $3.085 \mathrm{~s}$ to $3.045 \mathrm{~s}$; when $P_{\mathrm{t} 3}=0.12-0.16 \mathrm{MPa}$, the time of the maximum temperature rise of TC-1 decreased more significantly, from $3.045 \mathrm{~s}$ to $2.871 \mathrm{~s}$.

The temperature rise and rate of temperature rise at the combustion chamber exit reflect the degree of flame temperature increase and rate of heat release of flame combustion; both are the key parameters responsible for successful ignition in the combustion chamber. Figure 8 shows that the curves of temperature rise and rate of temperature rise at the combustion chamber exit have identical trends. Regardless of the change in inlet pressure, the temperature rise and rate of temperature rise of TC- 1 are the largest, and those of TC- 3 are the smallest. However, as the inlet pressure increased, the difference in the trend significantly varied among the thermocouples. When $P_{\mathrm{t} 3}=0.04 \mathrm{MPa}$, the maximum temperature increase and rate of temperature rise at the combustion chamber exit were only $12.8^{\circ} \mathrm{C}$ and $11.98 \mathrm{~K} / \mathrm{s}$, respectively, indicating ignition failure in the combustion chamber. When $P_{\mathrm{t} 3}=0.6-0.08 \mathrm{MPa}$, the temperature rise and rate of temperature rise of TC-1 increased slowly from $148.4^{\circ} \mathrm{C}$ to $231.6^{\circ} \mathrm{C}$ and from $55.64 \mathrm{~K} / \mathrm{s}$ to $85.74 \mathrm{~K} / \mathrm{s}$, respectively. When $P_{\mathrm{t} 3}=0.08-0.1 \mathrm{MPa}$, the temperature rise and rate of temperature rise of $\mathrm{TC}-1$ increased rapidly from $231.6^{\circ} \mathrm{C}$ to $448.8^{\circ} \mathrm{C}$ and from $85.74 \mathrm{~K} / \mathrm{s}$ to $164.69 \mathrm{~K} / \mathrm{s}$, respectively. 


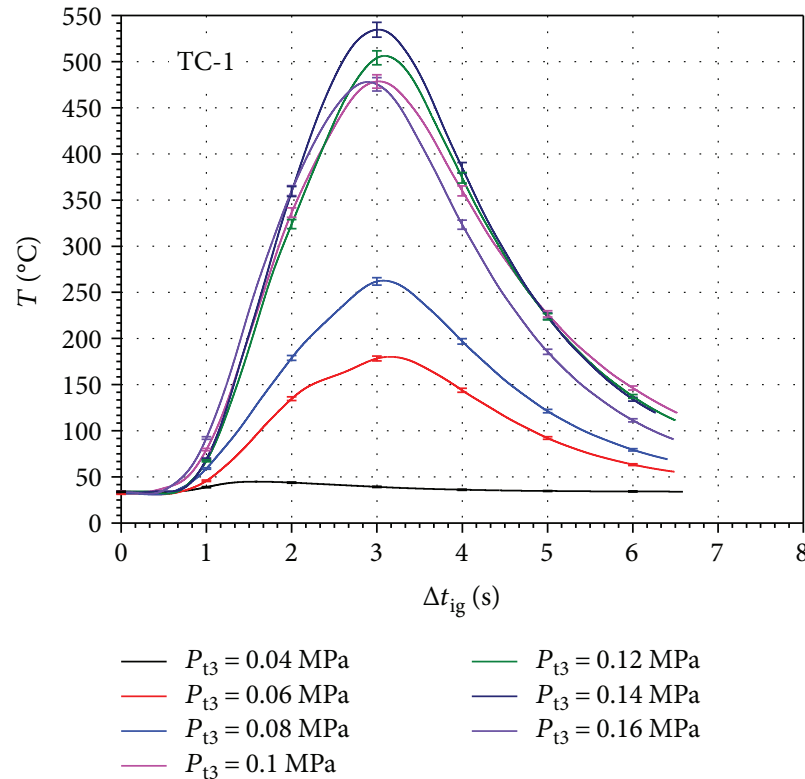

(a)

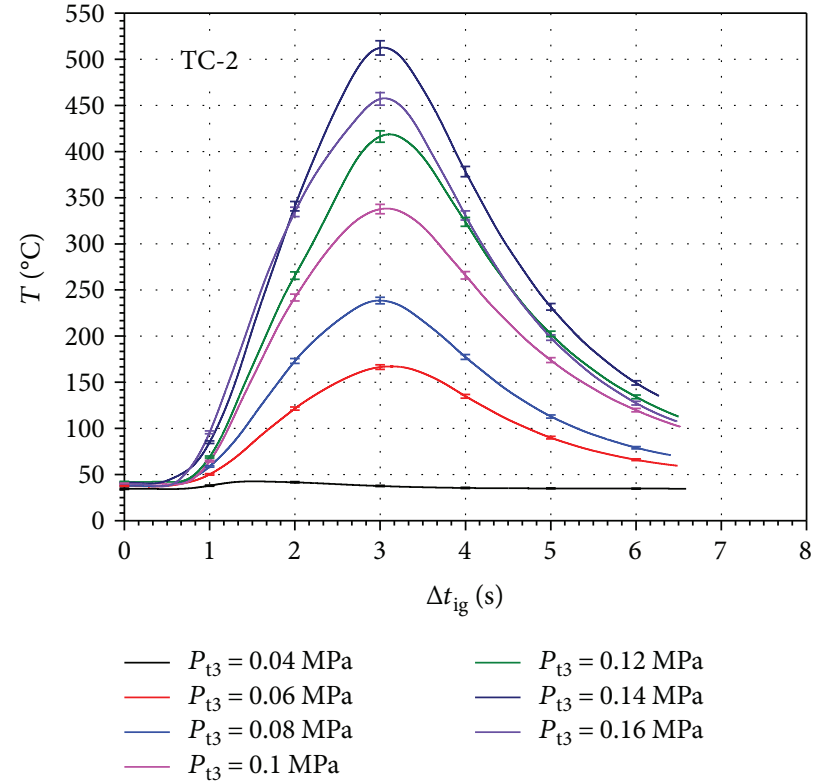

(b)

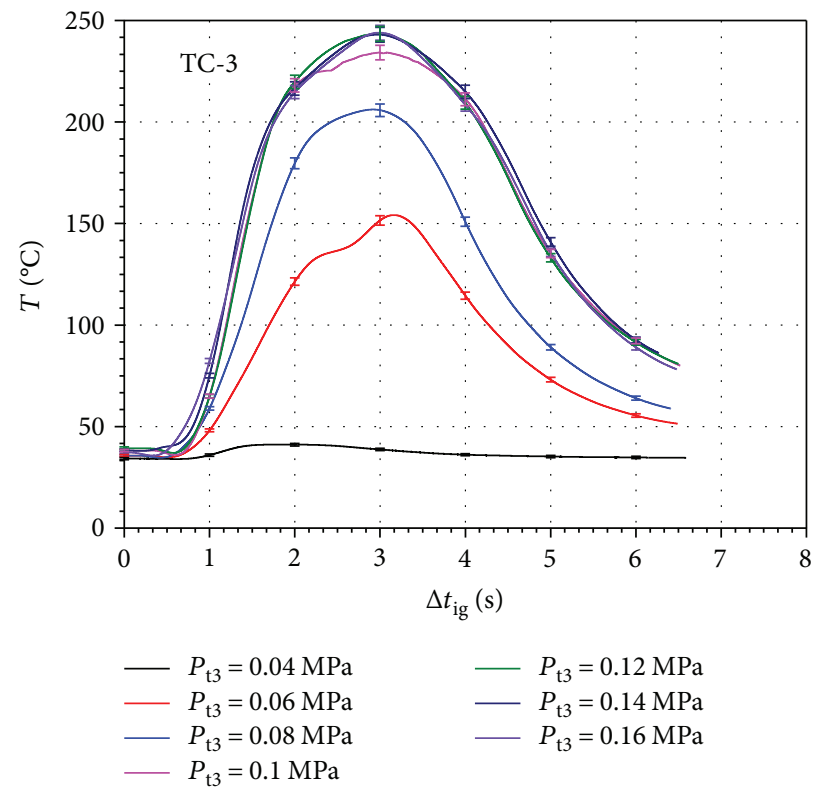

(c)

FIgURE 6: Temperature profiles at the combustion chamber exit. (a) TC-1 thermocouple, (b) TC-2 thermocouple, and (c) TC-3 thermocouple.

When $P_{\mathrm{t} 3}=0.1-0.14 \mathrm{MPa}$, the increase in the temperature rise and rate of temperature rise of TC- 1 increased slowly, from $448.8^{\circ} \mathrm{C}$ to $505.4^{\circ} \mathrm{C}$ and from $164.69 \mathrm{~K} / \mathrm{s}$ to $186.77 \mathrm{~K} / \mathrm{s}$, respectively. When $P_{\mathrm{t} 3}=0.1-0.14 \mathrm{MPa}$, the temperature rise and rate of temperature rise of TC- 1 started to decrease, from $505.4^{\circ} \mathrm{C}$ to $448.8^{\circ} \mathrm{C}$ and from $186.77 \mathrm{~K} / \mathrm{s}$ to $173.6 \mathrm{~K} / \mathrm{s}$, respectively. When $P_{\mathrm{t} 3}=0.06-0.14 \mathrm{MPa}$, the temperature rise and rate of temperature rise of TC-2 increased rapidly from $134.4^{\circ} \mathrm{C}$ to $484.2^{\circ} \mathrm{C}$ and from $51.97 \mathrm{~K} / \mathrm{s}$ to $176.39 \mathrm{~K} / \mathrm{s}$, respectively. When $P_{\mathrm{t} 3}=0.14-0.16 \mathrm{MPa}$, the temperature rise and rate of temperature rise of TC-2 decreased from $484.2^{\circ} \mathrm{C}$ to $427.1^{\circ} \mathrm{C}$ and from $176.39 \mathrm{~K} / \mathrm{s}$ to $154.69 \mathrm{~K} / \mathrm{s}$, respectively. When $P_{\mathrm{t} 3}=0.06-0.1 \mathrm{MPa}$, the temperature rise and rate of temperature rise of TC-3 increased slowly from $121.4^{\circ} \mathrm{C}$ to $203.9^{\circ} \mathrm{C}$ and from $49.77 \mathrm{~K} / \mathrm{s}$ to $78.93 \mathrm{~K} / \mathrm{s}$, respectively. When $P_{\mathrm{t} 3}=0.1-0.16 \mathrm{MPa}$, the temperature rise and rate of temperature rise of $\mathrm{TC}-3$ increased slightly from $212.6^{\circ} \mathrm{C}$ to $216.9^{\circ} \mathrm{C}$ and from $78.93 \mathrm{~K} / \mathrm{s}$ to $80.96 \mathrm{~K} / \mathrm{s}$, respectively.

Through the abovementioned description of the effects of inlet pressure on the ignition process in the combustion chamber, either the trends of the growth rate of flame area and centroid location or the temperature value, rate of temperature rise, and starting time of temperature rise on radial direction at the combustion chamber are not isolated; all these parameters are interconnected. For example, the fuel/ 


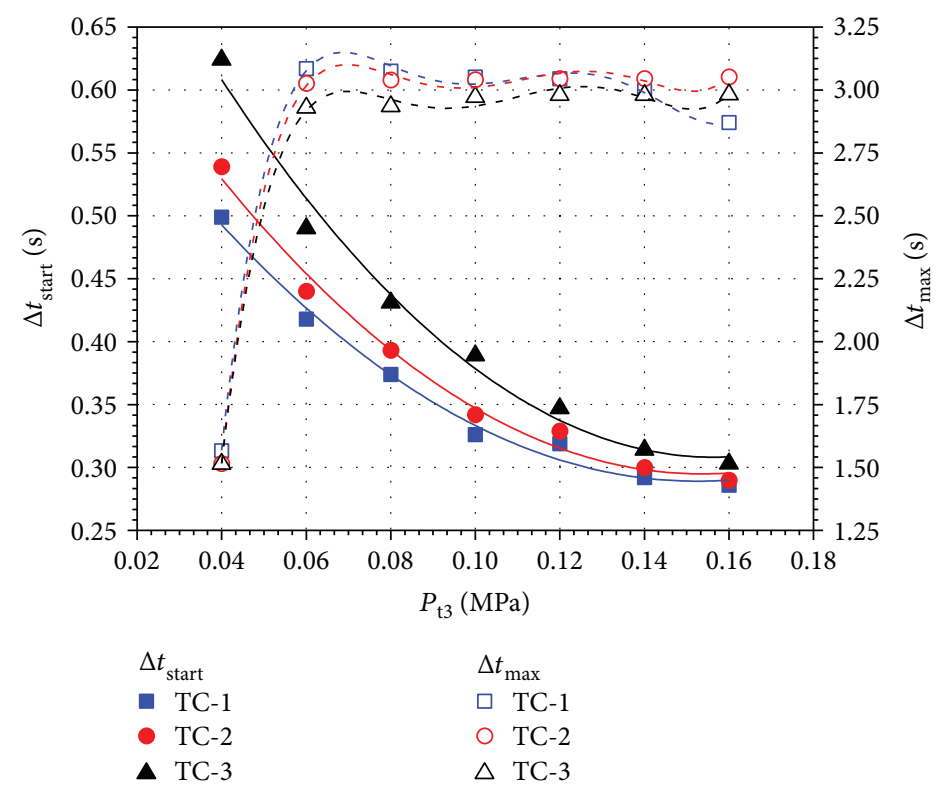

FIGURE 7: Effect of inlet pressure on the time of temperature rise at the combustion chamber exit.

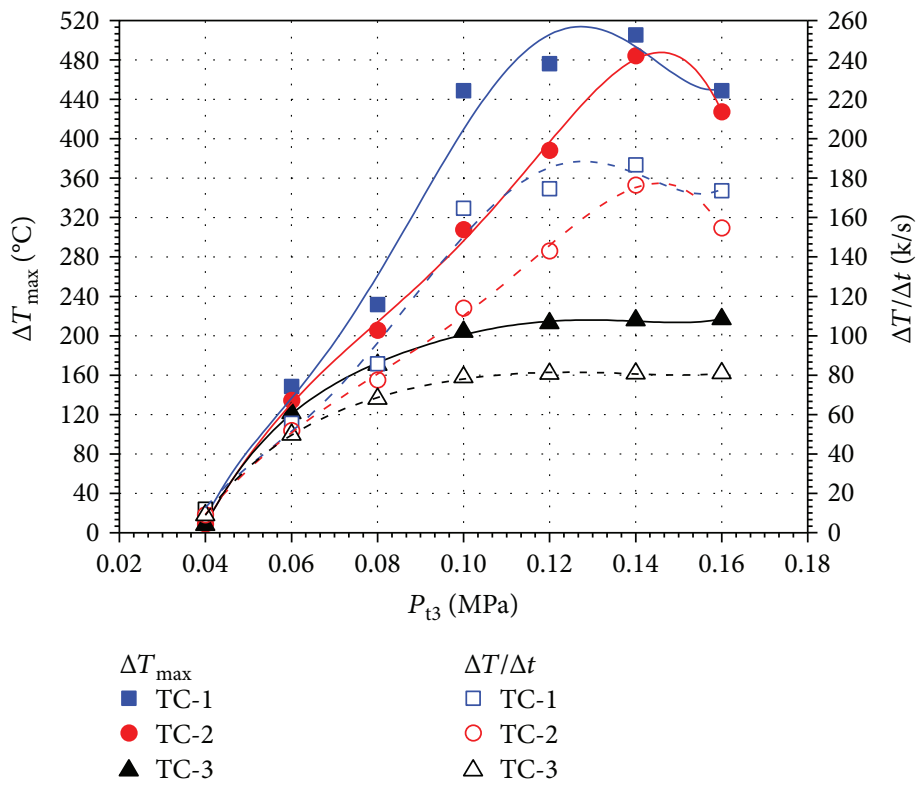

FIGURE 8: Effect of inlet pressure on the maximum temperature rise and maximum rate of temperature rise at the combustion chamber exit.

air ratio of the combustible mixed gas in the combustion chamber and the heat release rate of the flame determine the maximum temperature rise and rate of temperature rise at the combustion chamber exit. The distribution of fuel and air in the combustion chamber determines the temperature distribution at the combustion chamber exit. All these are related to the fuel evaporation rate and chemical reaction rate of combustion. Besides, in the formation phase of the initial flame, the initial atomization quality of the nozzle and chemical reaction rate of the initial flame kernel directly affected the formation time of the initial flame and centroid location, thus further affecting the starting time of temperature rise at the combustion chamber exit. In the high-speed development phase of the flame, the fuel evaporation rate, combustion chemical reaction rate, and distribution of fuel and air affected the motion trace of centroid and growth rate of the flame area in the flame development process. In the stable development phase of the flame, the number and the size of large drops affected the growth rate of the flame area and time of the maximum temperature rise at the combustion chamber exit. Therefore, the influence of inlet pressure on the atomization quality of the nozzle and combustion chemical reaction rate is the main reason for the difference in the ignition process in the combustion chamber.

The effect of ambient pressure on the atomization of pressure-swirl atomizer was discovered long ago by relevant 


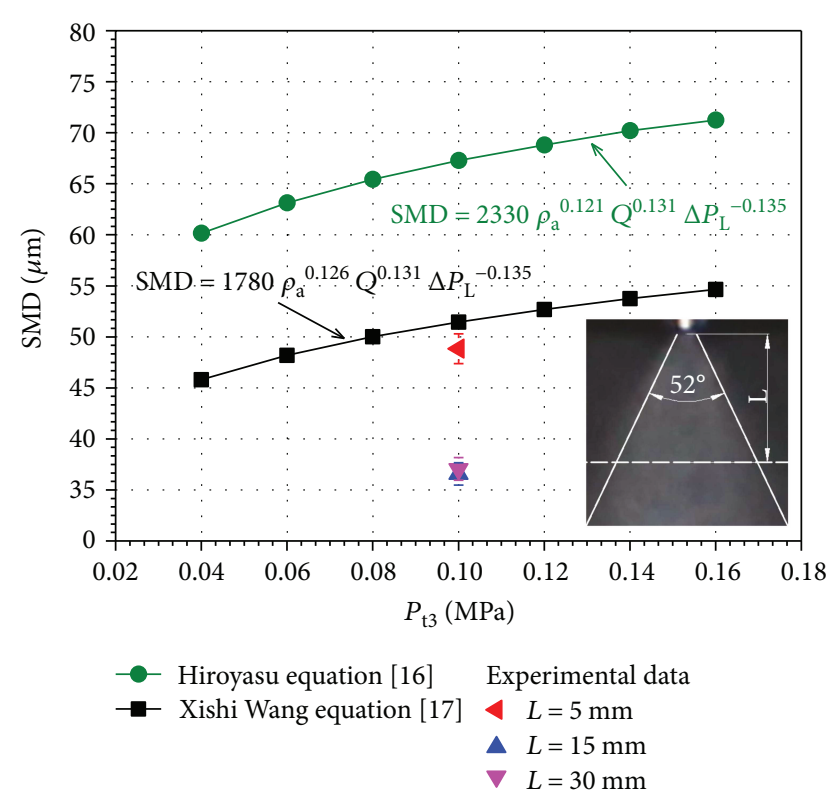

FIGURE 9: Variation in SDM with inlet pressure.

scholars, and many researches have extensively investigated this issue. The results show that [15-20] when the ambient pressure is higher than the standard atmospheric pressure $\left(P_{\mathrm{a}}=0.1-0.4 \mathrm{MPa}\right)$, the SMD at the exit of the pressureswirl atomizer increased with ambient pressure, and the spray cone angle gradually decreased. The relationship between SMD and ambient pressure and that between SMD and air density can be expressed as $\mathrm{SMD} \approx P_{\mathrm{a}}^{0.27}$ and $\mathrm{SMD} \approx \rho_{\mathrm{a}}{ }^{0.126}$, respectively. When the ambient pressure was lower than the standard atmosphere $\left(P_{\mathrm{a}}=0.04-0.1 \mathrm{MPa}\right)$, the SMD at the exit of the pressure-swirl atomizer decreased with ambient pressure, and the relationship between SMD and air density can be expressed as $\mathrm{SMD} \approx \rho_{\mathrm{a}}{ }^{0.121}$.

Before the ignition test in the combustion chamber, the atomization performances of the pressure-swirl atomizer under ambient temperature and standard pressure were investigated using a Malvern laser particle size analyzer. The values of SMD were measured at various distance from the pressure-swirl atomizer: $5 \mathrm{~mm}, 15 \mathrm{~mm}$, and $30 \mathrm{~mm}$. When $\Delta P_{\mathrm{L}}=0.8 \mathrm{MPa}$, the values of $\mathrm{SMD}$ were $48.83 \mu \mathrm{m}$, $36.57 \mu \mathrm{m}$, and $37.06 \mu \mathrm{m}$, respectively. Considering the calculated results using the formulas for the nozzle SMD proposed by Hiroyasu et al. and Wang et al. as the reference [16, 17], the difference between the present result and that obtained using Xishi Wang's formula is only $2.62 \mu \mathrm{m}$, as shown in Figure 9. Irrespective of the calculation method used, the initial SMD of the nozzle increased with the increase in ambient pressure. Considering the SMD under standard atmosphere as the base, the maximum decrease rate and maximum increase rate are $10 \%$ and $6 \%$, respectively.

As the inlet pressure increased, the SMD at the nozzle outlet gradually increased, that is, the size and quantity of large drops at the nozzle outlet gradually increased, whereas the quantity of small drops decreased. The penetration depth of small drops at the nozzle outlet was small; therefore, the small drops moved downstream towards the combustion chamber. These small drops were located around the top of the combustion chamber. These small drops evaporated faster; therefore, they mixed with the air flow around the spark plug and formed a mixed gas that was suitable for ignition. Moreover, as the quantity of small drops increased, the local fuel/air ratio near the spark plug gradually increased and approached the stoichiometric ratio. This contributed to the increase in the chemical reaction rate of the initial flame kernel. However, the large drops at the nozzle outlet penetrated strongly and did not move downstream towards the combustion chamber with air flow but continued to move radially in the combustion chamber. They were broken into many smaller drops in the relative motion with air flow and mixed with the air flow. As the size of drops increased, the breakup length increased. Therefore, as the size of drops and quantity of large drops increased, the distribution of fuel and air in the combustion chamber gradually developed along the radial direction in the combustion chamber. Besides, with the increase in the quantity of the initial large drops and size of the drops of the nozzle, owing to the low evaporation rate of large drops, the fuel/air ratio near the spark plug decreased, hindering the increase in the chemical reaction rate of the initial flame kernel. Moreover, the chemical reaction rate $v \propto P_{\mathrm{a}}{ }^{n}$ ( $n$ is the order of reaction), that is, the chemical reaction rate increased with inlet pressure.

In the formation phase of the initial flame, when $P_{\mathrm{t} 3}=0.04-0.06 \mathrm{MPa}$, the initial SMD of the nozzle was low, but a decrease in inlet pressure decreased the chemical reaction rate of the initial flame kernel and further resulted in the long formation time of the initial flame. When $P_{\mathrm{t} 3}=0.08-0.16 \mathrm{MPa}$, the initial SMD of the nozzle gradually increased, and the increase in both the drop size and quantity of large drops led to an increase in the penetration depth and crumbling distance of drop, inducing a radial deviation of the centroid coordinates of the initial flame in the combustion chamber. Particularly when $P_{\mathrm{t} 3} \geq 0.14 \mathrm{MPa}$, this deviation was significant. Because the formation time of the initial flame was the time when the combustion heat release started to increase, the formation time of the initial flame determined the starting time of the temperature rise of the thermocouples at the combustion chamber exit. The formation location of the initial flame determined the difference in the starting times of the thermocouples located at different radial positions of the combustion chamber exit. When $P_{\mathrm{t} 3}=0.04-$ $0.06 \mathrm{MPa}$, the formation time of the initial flame was relatively long; therefore, the starting times of the temperature rise of the thermocouples located at the combustion chamber exit were relatively large. When $P_{\mathrm{t} 3}=0.08-0.16 \mathrm{MPa}$, the initial flame was formed at 3-4 ms after the spark plug was discharged; however, based on the curve of the starting time of the temperature rise at the combustion chamber exit, it can be derived that the formation time of the initial flame gradually shortened. Moreover, when $P_{\mathrm{t} 3}=0.14-0.16 \mathrm{MPa}$, the centroid of the initial flame distinctly moved along the radial direction in the combustion chamber, and therefore the starting time of the temperature rise of TC- 2 and TC- 3 gradually approached to that of TC-1. Hence, in the formation phase of the initial flame, the effect of inlet pressure on the chemical reaction rate is the main factor affecting the formation time 
of the initial flame, and the variation in SMD at the nozzle outlet is the main factor accounting for the difference in the formation location of the initial flame.

In the high-speed development phase of the flame, the increase in inlet pressure accelerated the chemical reaction rate of the flame, so the heat release rate of the flame would increase. On the one hand, the viscosity of fuel decreases when the temperature raises (as shown in Table 1), and the low viscosity has better atomization performance [5]. On the other hand, the evaporation rate of the fuel increased rapidly when the temperature raises (as shown in Table 1). The burning rate and heat release rate of the flame would be accelerated by their promotion. Thus, as the inlet pressure increases, the maximum growth rate of the flame area gradually increases, and the time for reaching the maximum gradually decreases. The development of the flame is closed related to the distribution of the fuel and air in the combustion chamber. As the inlet pressure increased, both the quantity and size of large drops at the nozzle exit gradually increased, and the penetration depth and crumbling distance of large drops also increased. The distribution of the fuel and air that was more suitable for combustion radially moved towards the combustion chamber. This led to a decrease in the axial distance between the centroid of the flame and combustion chamber downstream, while increasing the related radial distance. Thus, in the high-speed development phase of the flame, the effect of inlet pressure on the chemical reaction rate is the main factor affecting the development speed of the flame, and the variation of SMD at the nozzle exit is the main factor affecting the development direction of the flame.

In the stable development phase, the small drops following the motion of air flow rapidly evaporated to participate in combustion, whereas the large drops continually underwent evaporation and combustion. All these phenomena determined the maximum temperature, rate of temperature rise, and time of the maximum temperature rise. When $P_{\mathrm{t} 3} \leq$ $0.14 \mathrm{MPa}$, the increase in inlet pressure accelerated the chemical reaction rate of the flame, promoted the evaporation rate of relatively large fuel particles following the motion of air flow, and enhanced the temperature and rate of temperature rise at the combustion chamber exit. When $P_{\mathrm{t} 3}=0.16 \mathrm{MPa}$, the increase in inlet pressure caused an increase in the air density. Although the chemical reaction of flame was accelerated by inlet pressure, the total fuel/air ratio in the combustion chamber significantly decreased, leading to a decrease in the temperature and rate of temperature rise. When $P_{\mathrm{t} 3}=0.06-0.16 \mathrm{MPa}$, a gradual increase in the quantity and size of large drops at the nozzle exit caused a gradual radial movement of relatively large drops following the motion of air flow towards the combustion chamber. Thus, the time of the maximum temperature rise of TC- 1 at the combustion chamber exit decreased, whereas those of TC-2 and TC-3 increased. Moreover, when $P_{\mathrm{t} 3}<0.14 \mathrm{MPa}$, an increase in the temperature in the combustion chamber accelerated the evaporation of fuel particles at the nozzle outlet. Some large fuel particles shrank during the radial movement towards the combustion chamber, moved towards the combustion chamber downstream with air flow, and then continued evaporation and participated in combustion, accelerating the radial movement of the centroid of the flame towards the combustion chamber. When $P_{\mathrm{t} 3} \geq 0.14 \mathrm{MPa}$, some large fuel particles at the nozzle exit quickly evaporated and moved with air flow towards the combustion chamber downstream, and thus a mixed gas suitable for flame development was formed along the axial direction of the combustion chamber, accelerating the axial movement of the centroid of the flame towards the combustion chamber downstream. Moreover, Figure 8 shows that the maximum temperature rise and rate of temperature rise of TC-3 increased slowly with inlet pressure. This is because as the temperature in the combustion chamber increased, the evaporation of fuel particles at the nozzle exit accelerated, and the large fuel particles gradually shrank in the radial movement towards the combustion chamber. Thus, the penetration depth decreased, and relatively less fuel reached the relatively lower part of the combustion chamber. Accordingly, the fuel/air ratio in the relatively lower part of the combustion chamber was low, and the combustion temperature was low without a significant increase. Hence, in the stable development phase of the flame, the effect of inlet pressure on the chemical reaction rate is the main factor affecting the temperature rise and rate of temperature rise at the combustion chamber exit, whereas the variation in SMD at the nozzle exit is the main factor affecting the time of maximum temperature rise at the combustion chamber exit and development direction of the centroid of the flame.

\section{Conclusions}

Under the inlet pressure condition $P_{\mathrm{t} 3}=0.04-0.16 \mathrm{MPa}$, the effects of inlet pressure on the ignition process of the combustion chamber were experimentally investigated in this study. Based on the growth rate of the flame area, the ignition process in the combustion chamber can be divided into three phases: (i) the formation phase of the initial flame, (ii) the high-speed development phase of the flame, and (iii) the stable development phase of the flame. As the inlet pressure increases, the time of the formation of the initial flame and growth rate of the flame area gradually decreases, and the centroid gradually moves radially towards the combustion chamber. The radial distances of the initial flame centroid gradually increased about $13 \%, 5 \%, 6 \%, 12 \%, 57 \%$, and $24 \%$. Besides, the formation time and location of the initial flame determine the starting time of the temperature rise of the thermocouples located at the combustion chamber exit and the difference in the starting times of the temperature rise of the thermocouples located at different radial positions. When $P_{\mathrm{t} 3}=0.04-0.14 \mathrm{MPa}$, before the growth rate of the flame area reaches the maximum, the centroid of the flame significantly moves towards the combustion chamber downstream. When the growth rate of the flame area reaches the maximum, the radial development of the centroid of the flame towards the combustion chamber is strengthened. When $P_{\mathrm{t} 3}=0.14-0.16 \mathrm{MPa}$, the centroid of the flame moves exactly in the direction opposite to that previously mentioned. After a successful ignition in the combustion chamber, the centroid of the flame first develops 
towards the combustion chamber downstream for some time and then moves towards the combustion chamber upstream. Moreover, the time of the centroid circulation of the flame gradually decreases as the inlet pressure increases. The starting time of temperature rise at the combustion chamber exit decreases as the inlet pressure increases. Moreover, that of TC- 1 is the smallest and that of TC-3 is the largest in all the cases. When $P_{\mathrm{t} 3}=0.06-0.16 \mathrm{MPa}$, the time of the maximum temperature rise of TC-1 at the combustion chamber exit gradually decreases, whereas those of TC-2 and TC-3 gradually increases. Under the condition of successful ignition $\left(P_{\mathrm{t} 3}=0.06-0.16 \mathrm{MPa}\right)$, as the inlet pressure increases, the maximum temperature rise increased by about $50 \%$, $58 \%, 12 \%, 11 \%$, and $-9 \%$, respectively. Meanwhile, the rate of temperature rise increased by about $47 \%, 54 \%, 11 \%$, $11 \%$, and $-7 \%$, respectively. Thus, the maximum temperature rise and temperature rise rate are determined by rate of the flame chemical reaction, rate of large drop evaporation, and fuel/air ratio. The research results would provide experimental data for using torch indirect ignition mode such as aero engines and burners, especially under negative pressure conditions. The influence of ambient pressure on flame propagation and temperature distribution at the exit could help them to optimize the structure for improving the success rate of ignition. In addition, the research results could also provide reference for direct ignition of nonswirling burners.

\section{Conflicts of Interest}

The authors declare that they have no conflicts of interest.

\section{Acknowledgments}

This work was supported by the National Natural Science Foundation of China, Grant no. 51476077.

\section{References}

[1] H. N. S. Rao and A. H. Lefebvre, "Ignition of kerosine fuel sprays in a flowing air stream," Combustion Science and Technology, vol. 8, no. 1-2, pp. 95-100, 1973.

[2] S. F. Ahmed and E. Mastorakos, "Spark ignition of lifted turbulent jet flames," Combustion and Flame, vol. 146, no. 1-2, pp. 215-231, 2006.

[3] S. F. Ahmed, R. Balachandran, T. Marchione, and E. Mastorakos, "Spark ignition of turbulent nonpremixed bluff-body flames," Combustion and Flame, vol. 151, no. 1-2, pp. 366-385, 2007.

[4] S. F. Ahmed, Ignition of Turbulent Non-Premixed Flame [Ph.D. thesis], University of Cambridge, England, UK, 2006.

[5] D. W. Naegeli and L. G. Dodge, "Ignition study in a gas turbine combustor," Combustion Science and Technology, vol. 80, no. 4-6, pp. 165-184, 1991.

[6] S. Choi, D. Lee, and J. Park, "Ignition and combustion characteristics of the gas turbine slinger combustor," Journal of Mechanical Science and Technology, vol. 22, no. 3, pp. 538544, 2008.

[7] H. Bao, J. Zhou, and Y. Pan, "The effect of kerosene injection on ignition probability of local ignition in a scramjet combustor," Acta Astronautica, vol. 132, pp. 54-58, 2017.
[8] A. Larsson, A. Berg, and A. Bonaldo, Fuel Flexibility at Ignition Conditions for Industrial Gas Turbines, Turbine Technical Conference and Exposition, San Antonio, TX, USA, 2013.

[9] B. Peterson, D. Reuss, and V. Sick, "On the ignition and flame development in a spray-guided direct-injection spark-ignition engine," Combustion and Flame, vol. 161, no. 1, pp. 240-255, 2014.

[10] A. H. Lefebvre, Gas Turbine Combustion, CRC press, New York, NY, USA, 1998.

[11] T. Marchione and E. Mastorakos, "Ignition of turbulent swirling n-heptane spray flames using single and multiple sparks," Combustion and Flame, vol. 156, no. 1, pp. 166-180, 2009.

[12] E. Mastorakos, "Spark ignition of turbulent non-premixed flames: experiments and simulations," Proceedings of the International Workshop, vol. 1990, no. 1, pp. 63-67, 2009.

[13] M. Philip, M. Boileay, R. Vicquelin et al., "Simulation of the ignition process in an annular multiple-injector combustor and comparison with experiments," Journal of Engineering for Gas Turbines and Power, vol. 137, article 031501, 2014.

[14] S. L. Deng, D. Han, and C. K. Law, "Ignition and extinction of strained nonpremixed cool flames at elevated pressures," Combustion and Flame, vol. 176, pp. 143-150, 2017.

[15] D. N. Nguyen, H. Ishida, and M. Shioji, "Ignition and combustion characteristics of gas-to-liquid fuels for different ambient pressures," Energy \& Fuels, vol. 24, no. 1, pp. 365-374, 2010.

[16] H. Hiroyasu and T. Katoda, "Fuel droplet size distribution in a diesel combustion chamber," SAE Transactions, article 74017, 1974.

[17] X. Wang and P. Zhu, "Effect of low ambient air pressure on spray characteristics of water mist," Experimental Thermal and Fluid Science, vol. 66, pp. 7-12, 2015.

[18] S. K. Chen and A. H. Lefebvre, "Influence of ambient air pressure on effervescent atomization," Journal of Propulsion and Power, vol. 9, no. 1, pp. 10-15, 1993.

[19] A. K. Jasuja and A. H. Lefebvre, "Influence of ambient air pressure on pressure-swirl atomizer spray characteristics," in Proceedings of ASME TURBO EXPO 2001: Power for Land, Sea, and Air: Volume 2: Coal, Biomass and Alternative Fuels; Combustion and Fuels; Oil and Gas Applications; Cycle Innovations, p. 7, New Orleans, LA, USA, 2001.

[20] B. Kegl, "Injection system design optimization by considering fuel spray characteristics," Journal of Mechanical Design, vol. 126, no. 4, pp. 703-710, 2004.

[21] H. H. Foster, "Effect of spark repetition rate on the ignition limits of a single tubular combustor," NACA-RM-E51J18, 1951.

[22] J. C. Armstrong and H. D. Wilsted, "Investigation of several techniques for improving altitude starting limits of turbojet engines," Cell Death \& Disease, vol. 2, no. 2, article e141, 1952.

[23] D. R. Ballal and A. H. Lefebvre, "Ignition and flame quenching in flowing gaseous mixtures," Proceedings of the Royal Society A: Mathematical, Physical and Engineering Sciences, vol. 357, no. 1689 , pp. 163-181, 1977.

[24] D. R. Ballal and A. H. Lefebvre, "Ignition of liquid fuel spray at subatmospheric pressure," Combustion and Flame, vol. 31, no. 2, pp. 115-126, 1978.

[25] R. K. Prasad, S. Jain, G. Verma, and A. K. Agarwal, "Laser ignition and flame kernel characterization of HCNG in a constant volume combustion chamber," Fuel, vol. 190, pp. 318-327, 2017. 
[26] V. Vukadinovic, P. Habisreuther, and N. Zarzalis, "Influence of pressure and temperature on laminar burning velocity and Markstein number of kerosene jet A-1: experiment and numerical study," Fuel, vol. 1113, pp. 401-410, 2013.

[27] O. Keiichi, H. Takehiro, and W. Toshinori, "Investigation of combustion and altitude-ignition performance of a small hydrogen-fueled reversed-flow turbine combustor," in 52nd Aerospace Sciences Meeting, pp. 1-9, National Harbor, MD, USA, 2014.

[28] M. Majcherczyk and F. Turrini, "Influence of the turbulence length scale and intensity on spark ignition of kerosene jet-A1-air mixtures at high altitude relight conditions," in ASME Turbo Expo 2014: Turbine Technical Conference and Exposition: Volume 4A: Combustion, Fuels and Emissions, p. 9, Dusseldorf, Germany, 2014. 


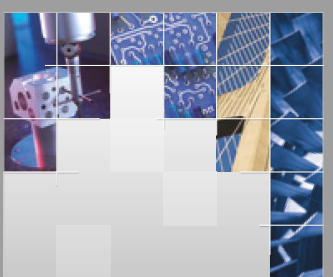

\section{Enfincering}
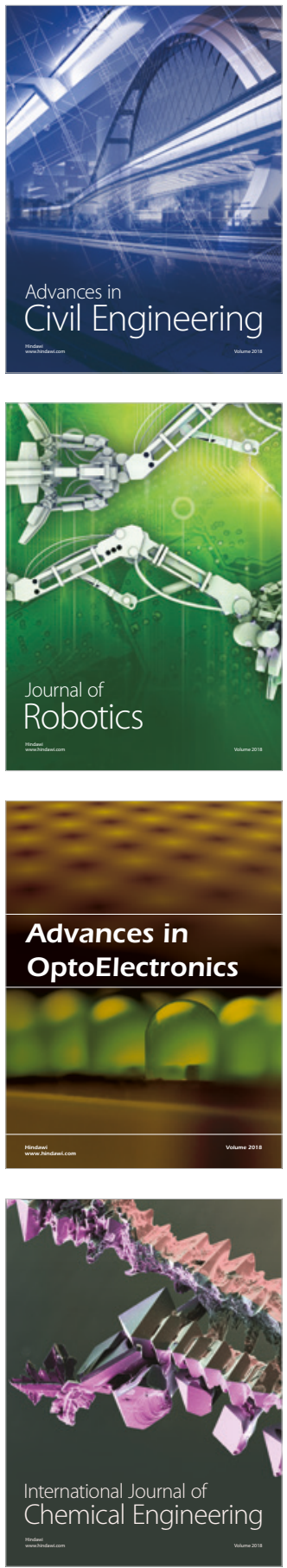

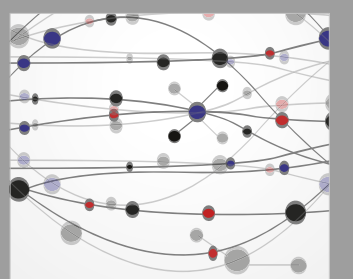

\section{Rotating \\ Machinery}

The Scientific World Journal

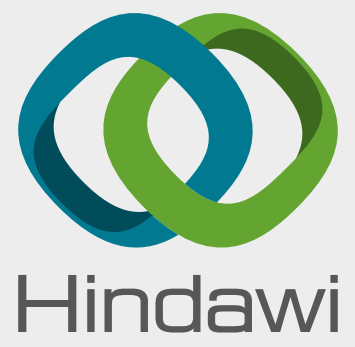

Submit your manuscripts at

www.hindawi.com
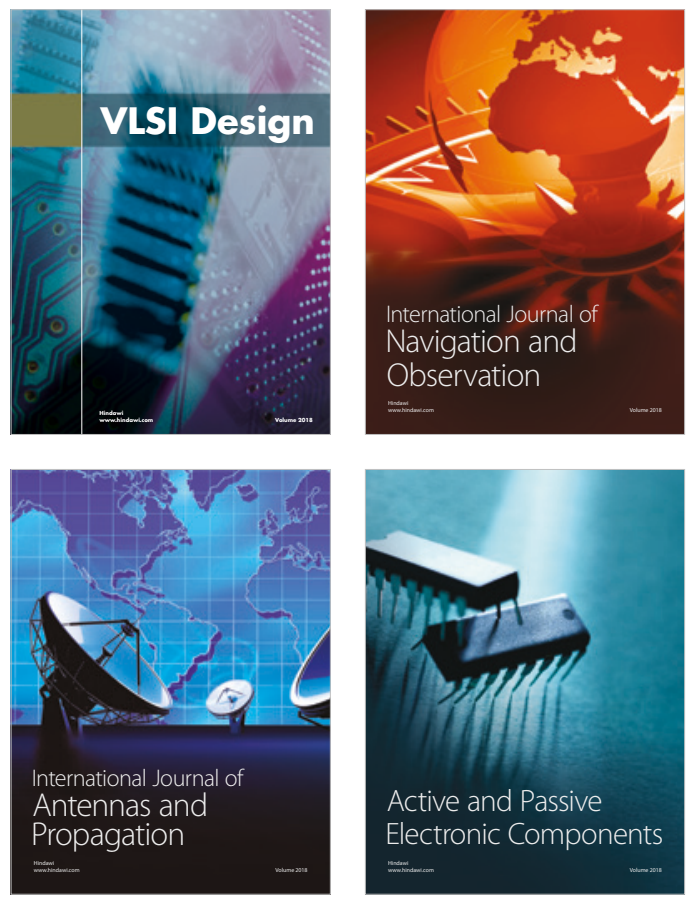
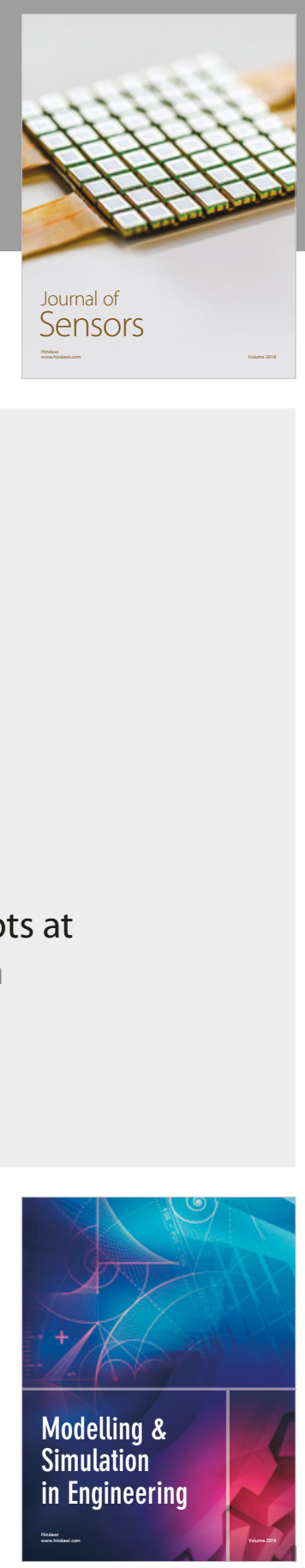

\section{Advances \\ Multimedia}
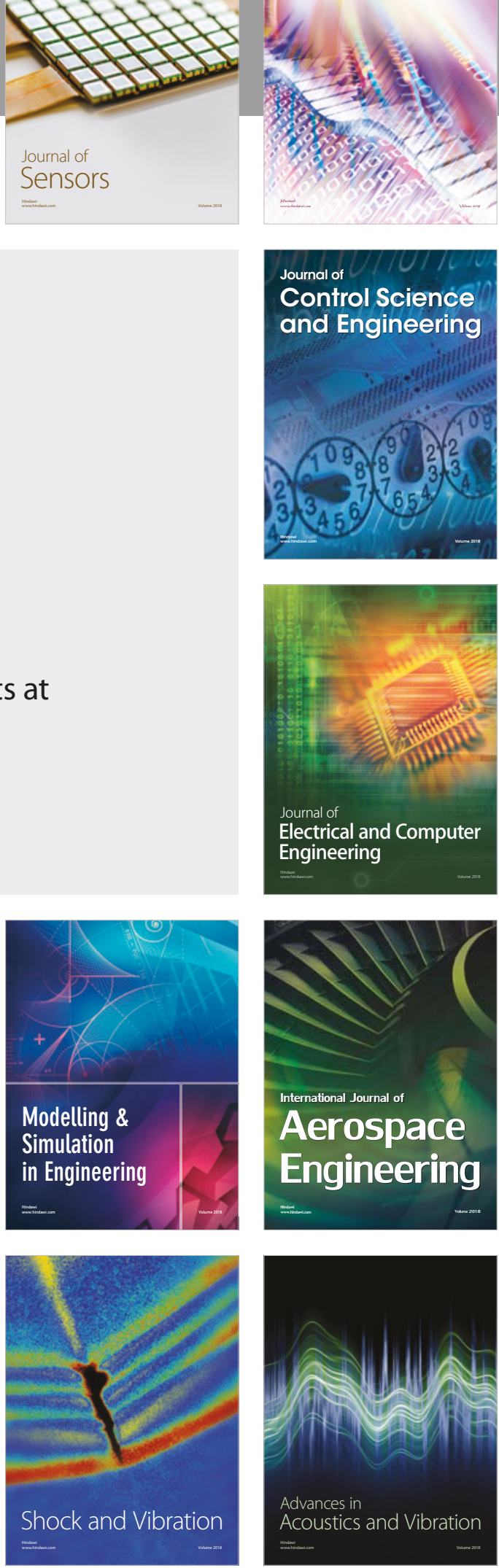